\section{Методика применения мотор-тестера МТ-5 для проверки элементов бесконтактной системы зажигания}

\author{
А. Э. Эгипти ${ }^{1}$ \\ Н. И. Серебрянский \\ А. А. Поттер \\ Петрозаводский государственный университет
}

\begin{abstract}
АННОТАЦИЯ
В статье рассматривается методика применения мотор-тестера МТ-5 для проверки элементов бесконтактной системы зажигания, содержащей электронный коммутатор.
\end{abstract}

Ключевые слова: зажигание, бесконтактное, коммутатор, электронный, работоспособность, осииллограф.

\section{SUMMARY}

The article considers methods of using motor-tester MT-5 for checking elements of noncontact system ignition with an electronic commutator.

Keywords: ignition, noncontact, commutator, electronic, fault-tolerance, oscillograph.

В бесконтактной системе зажигания, применяемой на автомобильных двигателях, одним из основных элементов является коммутатор. Коммутатор (типа 36.3734 или 3620.3734 , а также НIM-52 или 56.3734, выполненный в виде интегральной микросхемы, и др.) служит для прерывания тока в первичной цепи катушки зажигания по сигналам датчикараспределителя. Коммутатор собран из отдельных элементов: транзисторов, микросхем, резисторов, конденсаторов, спаянных в общую схему на печатной плате.

Для прерывания тока служит мощный высоковольтный транзистор КТ-848А, специально разработанный для системы зажигания высокой энергии. В схеме коммутатора имеется устройство для автоматического регулирования периода накопления тока в катушке зажигания в зависимости от частоты вращения коленчатого вала двигателя.

В процессе эксплуатации двигателя возникает необходимость проверить работу коммутатора. Он может быть проверен с помощью лампочки $3 . . .5$ ватт, подключенной последовательно первичной обмотке катушки зажигания. Мигание лампочки при проворачивании коленчатого вала стартером свидетельствует о рабочем состоянии коммутатора. Эта проверка дает

\footnotetext{
${ }^{1}$ Авторы - соответственно доценты кафедры технологии металлов и ремонта и доцент кафедры технологии и оборудования лесного комплекса

(c) А. Э. Эгипти, Н. И. Серебрянский, А. А Поттер, 2003
}

грубую оценку работоспособности. На работу двигателя влияют параметры импульсов тока: сила, длительность, форма

Если форма импульсов коммутатора искажена, то могут быть перебои с искрообразованием или оно может происходить с запаздыванием. При этом двигатель будет перегреваться и не будет развивать номинальной мощности.

Типовая схема просмотра осциллограммы первичной цепи бесконтактной системы зажигания с магнитоэлектрическим датчиком Холла здесь не применима. Особенностью осциллографа прибора МТ-5 является одновременное включение схемы горизонтальной и вертикальной разверток. На кафедре ТМиР ПетрГУ разработана схема просмотра формы импульса тока с коммутатора и определения его параметров с применением мотор-тестера МТ-5 Новгородского завода ГАРО. Проверка производится с применением стенда КИ-968. Схема соединений показана на рис. 1. Используется аккумулятор 1, катушка зажигания 2, электронный коммутатор 3 , генератор прямоугольных импульсов (ГПИ) 4, осциллограф МТ-5 5, разрядник 12 .

При диагностировании первичной цепи бесконтактной системы зажигания зажим "Пр" жгута первичной цепи 16 соединяется с выводом "1" коммутатора, датчик импульсов 15 - с проводом свечи зажигания первого цилиндра. При этом формирователь 13 выдает сигнал и при нажатии кнопки S3 переключателя 11 просмотра осциллограммы с наложением всех цилиндров от генератора пилообразного напряжения (ГПН) 10 через усилитель 8 запускается горизонтальная развертка осциллографа.

При нажатии кнопок S4 переключателя 7 (2, 40 или $400 \mathrm{~V}$ ) сигнал от усилителей 9 и 6 подается на катушку вертикального отклонения осциллографа. На экране видна осциллограмма напряжения в первичной цепи в виде синусоиды.

При просмотре формы импульса тока коммутатора используется возможность раздельного включения схемы горизонтальной развертки и схемы вертикального отклонения. Для этого применяется следующая схема включения:

- зажим "М" жгута первичной цепи подключается к "-" аккумулятора;

- зажим "Б" жгута первичной цепи подключается к "+" аккумулятора;

- зажим "Пр" жгута первичной цепи подключается к выводу "2" коммутатора; датчик импульсов первого цилиндра подключается на высоковольтный провод катушки зажигания.

Генератор прямоугольных импульсов 4 и остальные элементы подключаются так, как показано на рис. 1.

Для просмотра формы импульса тока коммутатора нужно нажать кнопки S3 переключателя 11 "hhh" и 
S4 (2V) переключателя 7. Формирователь 13 выдает сигнал, запускается схема горизонтальной развертки и схема вертикального отклонения. При нормальной работе проверяемого коммутатора на разряднике стенда появится искра, на экране осциллографа импульсы тока коммутатора. Правильность работы коммутатора оценивается сравнением полученной осциллограммы с эталонной.

Генератор прямоугольных импульсов (рис. 2) собран на операционном усилителе ДА-1 типа К140УД1Б. Работает по принципу создания положительной обратной связи, подаваемой на вход операционного усилителя. Частота генерации регулируется резистивно-емкостными цепями электронной схемы. Вырабатывается десять фиксированных частот: $4,5,6$, $10,20,36,48,88,103,211$ Гц, которые имитируют частоту вращения коленчатого вала двигателя.

При включенном выключателе В1 с помощью переключателя S1 выбирается первая часть диапазона, в положении выключателя В1 - вторая часть (от 88 до 211 Гц). Скважность импульсов регулируется с помощью потенциометра R7. Для имитации системы электронного зажигания скважность принята равной одной трети с использованием положительного фронта импульса.
Для согласования ГПИ с проверяемым коммутатором автомобиля и увеличения его нагрузочной способности использован буферный усилитель тока в виде эмитерного повторителя на базе операционного усилителя ДА-2 и выходного с помощью резистора R16, выведенного на панель прибора. Питание генератора осуществляется от двуполярного источника напряжением 12 вольт.

При наличии стендов КИ-968 или СПЗ-8 проверку коммутатора можно выполнить с их применением.

Используется аккумулятор, эталонная катушка зажигания, разрядник стенда. По амперметру стенда можно отградуировать шкалу экрана осциллографа по току.

\section{СПИСОК ЛИТЕРАТУРЫ}

1. Лихачев В. Д. Практические схемы на операционных усилителях. М.: Изд-во ДОСААФ, 1981. $80 \mathrm{c}$.

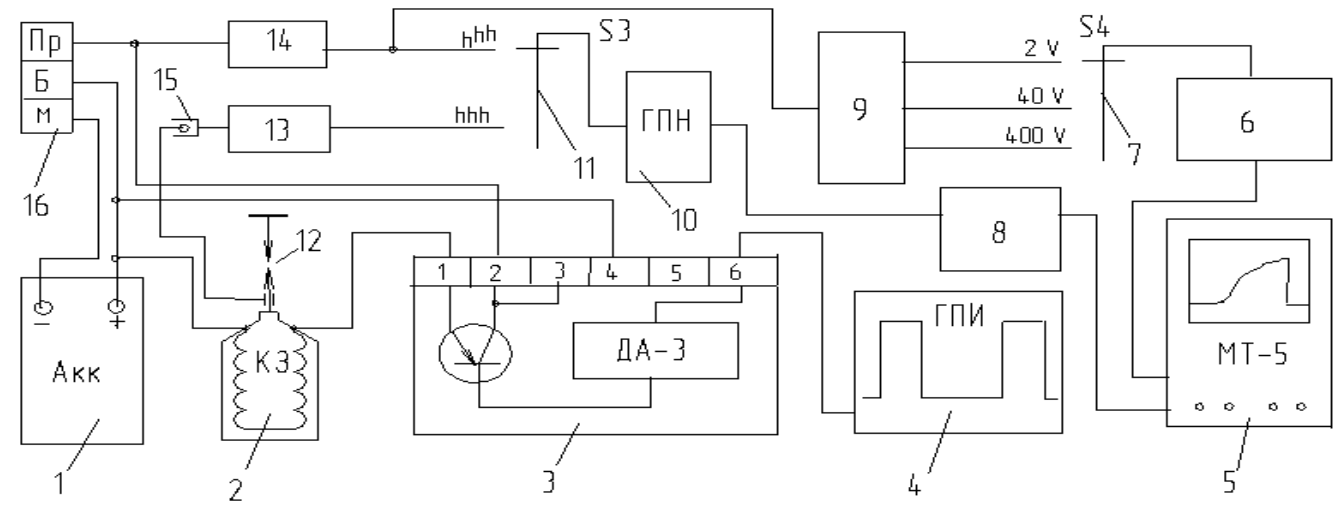

Рис. 1. Схема соединений элементов при проверке коммутатора

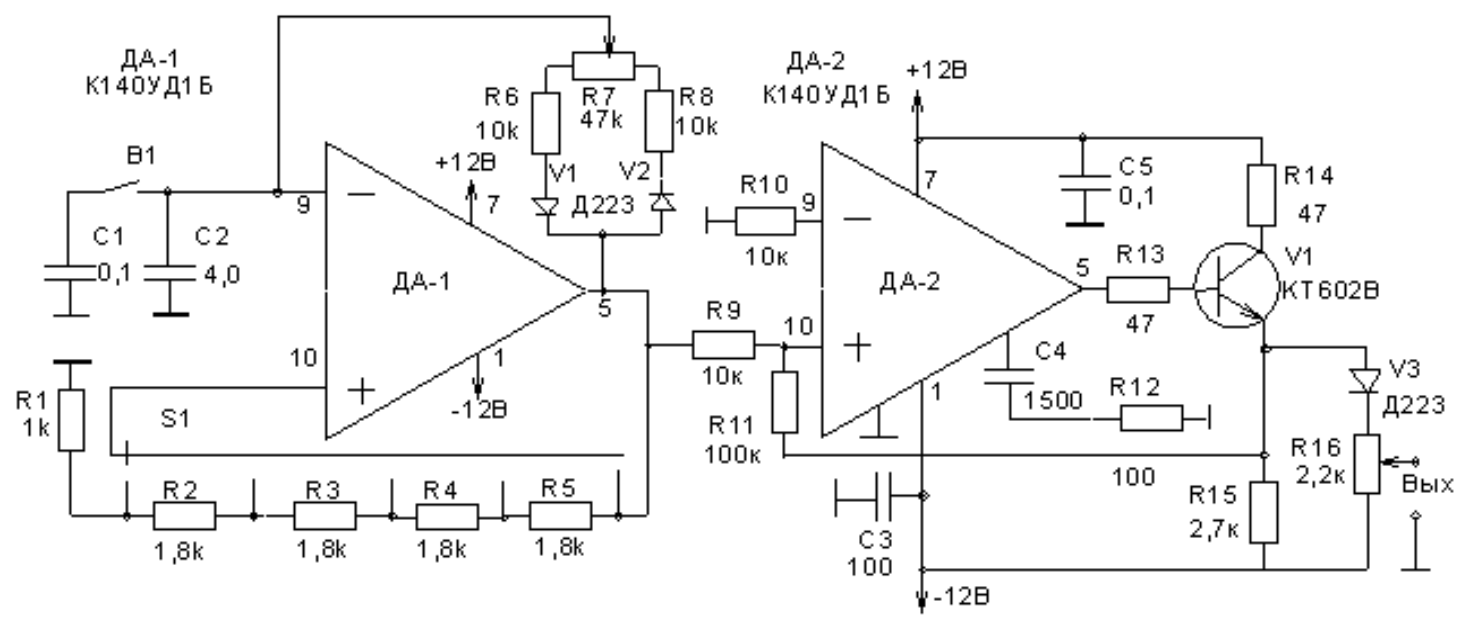

Рис. 2. Схема генератора прямоугольных импульсов 
